\title{
Changes in Children with Autism Spectrum Disorder after Theraplay Application
}

\author{
Yoonyoung Chang ${ }^{1}$, Bongseog Kim', and Miwon Youn ${ }^{2}$ \\ ${ }^{1}$ Department of Psychiatry, Sanggye Paik Hospital, Inje University College of Medicine, Seoul, Korea \\ ${ }^{2}$ Youn's Theraplay Counseling Center, Seoul, Korea
}

\begin{abstract}
Objectives: This study identified changes in social communication and interaction among children with autism spectrum disorder (ASD) through Theraplay.

Methods: This study included 20 children who were diagnosed with ASD by a child and adolescent psychiatrist and were recommended to undergo Theraplay in 2012-2017. The Marschak interaction method was used to identify and analyze the interactions between parents and their children. The Korean version of the Social Communication Questionnaire (K-SCQ) was used to evaluate symptoms of ASD. The Wilcoxon signed-rank test was used to compare the differences before and after Theraplay.

Results: Upon comparing the differences in total K-SCQ scores, there were statistically significant changes $(\mathrm{z}=-3.269$, $\mathrm{p}=0.001)$ in children with ASD. Changes were also confirmed in each category, namely social interaction, communication, and limited and repetitive behavior patterns $(\mathrm{p}=0.011, \mathrm{p}=0.025, \mathrm{p}=0.039$, respectively).

Conclusion: This study found that Theraplay may cause significant changes in social communication in children with ASD. Further studies are needed to establish the effectiveness of Theraplay in children with ASD.
\end{abstract}

Key Words: Theraplay; Marschak interaction method; Social communication.

Received: January 4, 2021 / Revision: February 13, 2021 / Accepted: March 30, 2021

Address for correspondence: Bongseog Kim, Department of Psychiatry, Sanggye Paik Hospital, Inje University College of Medicine, 1342 Dongil-ro, Nowon-gu, Seoul 01757, Korea

Tel: +82-2-950-1082, Fax: +82-2-936-8069, E-mail: kimbs328@paik.ac.kr

\section{INTRODUCTION}

Autism spectrum disorder (ASD) is a chronic neurodevelopmental disorder that occurs in early childhood and is also known as pervasive developmental disorder [1-3]. The characteristics of ASD include continuous damage to mutual social communication, interaction and the behavior or interest in a limited and repetitive form [1]. These symptoms appear in early childhood, causing limitations or damage to everyday functions [4]. The prevalence rate of ASD worldwide is about one in every 160 children and has been increasing over the last 20 years [5]. So far, there has been no established treatment for the key symptoms of the disease [3]. Various sociopsychological interventions have been proposed, and studies have shown the effectiveness of early intervention, such as Applied Behavior Analysis [6], Treatment and Education of Autistic and Related Communication Handicapped Children [7], Picture Exchange Communication System [8], and Early Start Denver Model [9]. Establishing evidence-based

This is an Open Access article distributed under the terms of the Creative Commons Attribution Non-Commercial License (https://creativecommons.org/licenses/by-nc/4.0) which permits unrestricted non-commercial use, distribution, and reproduction in any medium, provided the original work is properly cited. treatments is important to ease the burden on the families of children and minimize public health expenses in the future [10].

Theraplay is a collection of active and fun games for children and parents that Ann Jernberg began in the late 1960s using healthy parent-child interactions as a model [11]. Early interactions between parents and children affect ego and personality development of the child [12]. Theraplay is an interactive activity based on parent-child attachment [13]. Theraplay is set in the theory of self-psychology, object-relationship, and attachment theory [11]. It deals with humans' basic desire for relationships [13], which involve treating mind and behavior based on four basic dimensions: structure, engagement, nurture, and challenge. In the Theraplay situation of autistic children, therapists accept verbal and nonverbal gestures of autistic children and make "coordinated responses" to elicit a voluntary response from autistic children. Studies have reported that these experiences are likely to improve the psychological stability of autistic children as well as their ability to interact with each other [14]. These are also effective in improving relationships between parents and children as well as in social deficits, attachment disorders, and ASDs [15]. 
A recent study [15] identified the effects of Theraplay on children with autism using the Marschak Interaction Method (MIM) [16]. It confirmed that short-term intervention in the Theraplay resulted in no change in ASD core symptoms and, separately, improved parent-child relationships. However, the limitations, namely having no measures of evaluation to be analyzed by applying these changes to the ASD characteristics, the small number of samples, the short duration of treatment, and the effect of the measurers, remained.

The limitations of previous studies were supplemented further in this study to materialize changes before and after Theraplay. We sought to assess the effectiveness of Theraplay in improving the social communication and interaction aspects of children with autism.

\section{METHODS}

\section{Participants}

This study included 20 children who participated in the Theraplay program between in 2012-2017. The children were diagnosed with ASD based on International Statistical Classification 10th Revision (ICD-10) by a child and adolescent psychiatrist before treatment. All 17 male and 3 female children were living in Seoul and Gyeonggi-do. Their parents voluntarily agreed to participate in this study among the psychiatric patients at Sanggye Paik Hospital. After explaining the purpose and method of the study, we received informed consent for participation in the study. This study was approved by the Research Ethics Review Committee of Inje University Sanggye Paik Hospital (IRB SGPAIK 201901-008-001).

\section{Research method}

\section{Theraplay}

In this study, Theraplay was performed on children from 2 years 4 months to 9 years and 10 months. In Theraplay, there are four dimensions to satisfy the needs of parents and children: structure, engagement, nurture, and challenge. 'Structure' seeks to provide reliable, predictable, and safe structures and controls for parents (e.g. regulations, restraint, etc.); 'engagement' is a coordinated and enjoyable experience to create strong bonds, best stimulation levels, and shared enjoyment (e.g. tickling, light throwing, etc.); 'nurture' is a warm, friendly, and empathetic response to a child's attachment and desire for control (e.g. hugging, shaking, etc.); and 'challenge' is to provide a safe base while encouraging children to make an effort, explore, and enjoy achievement (e.g. challenging activities, etc.) [11]. In general, Theraplay consists of 18-24 sessions, with 3-4 assessment periods, treat- ment periods, and 4-6 follow-up inspections over a year [11]. In this study, a total of 20 Theraplay sessions were performed during an average of 6 months with their mothers. Post-treatment evaluation was immediately conducted after Theraplay was completed.

\section{MIM}

The MIM is an observation tool designed by Marschak in 1958 to assess the relationship between parents and children. The MIM evaluation was standardized by psychologists [16] after Ann Jernberg [11], founder of Theraplay, and expanded the use of MIM. MIM is a tool to learn how the four dimensions (structure, engagement, nurture, and challenge) in everyday life are performed in parent-child interactions. The therapist presents a play task that corresponds to each dimension and then identifies how well parents and children perform the play task while it is being carried out and whether the two are enjoying it together.

This study used MIM, a structured observation tool designed to identify and analyze the quality and characteristics of relationships between children and their respective caregivers during the baseline assessment and post-treatment assessment phase. According to the MIM, two of the parentchild pairs (mother-child, father-child) are required to perform the eight-to-nine pre-prepared tasks for 30-45 minutes; in this study, the mother-child pair was required to perform the eight tasks for 30 minutes. One or two dimensions of Theraplay were applied to each task. The contents of the eight MIM tasks used in this study are presented in Table 1.

\section{Evaluation scale}

In this study, the Korean version of the Social Communication Questionnaire (SCQ) (K-SCQ) [17] was used to examine the core symptoms of ASD that changed before and after the Theraplay focused on interaction. Diagnostic tools used domestically and abroad to diagnose ASDs include the Automatic Diagnostics Schedule [18] and Autism Diagnostic Interview-Revised [19]. However, the evaluation process takes a long time, and it is difficult to determine the degree of treatment for children before and after treatment. The SCQ is an excellent method of measurement of ASD symptoms [20]. Its validity has been proven in Korea as well [21]. Although the scale can be scored by a parent report without the help of an expert, in this study, doctors evaluated the scale based on the MIM video. The K-SCQ consists of 40 questions. Among them, 36 questions were divided into three subcategories (communication, social interaction, and limited and repetitive behavioral patterns), except for questions 1, 17, 18, and 38. Each question should be answered by "Yes" or "No", and the higher the score, the worse the ASD-related symptoms. More- 
over, in principle, there is a cut-off score of 15 or more points that classifies it as an ASD risk group (In the Korean version of the study, 10 points for $<47$ months old and 12 points for $>48$ months old) [17]. Children who participated in this study were diagnosed with autism by a child and adolescent psychiatrist before being commissioned to the Theraplay, and this scale was used only to compare the condition of the pre- and post-treatment patients.

A total of 40 questions in SCQ can be divided into three subcategories, except for four questions: the social interaction category of 15 questions, the communication category of 13 questions, and the limited and repetitive behavioral pattern category of 8 questions [17]. In this study, we identified the total score of SCQ before and after treatment, as well as the change in scores for each subcategory.

\section{Evaluation}

A therapist conducted MIM on 20 children in the study, and it was evaluated using a K-SCQ. The MIM was implemented at the time of the first visit. Immediately after the completion of Theraplay, the MIM was re-examined. To maintain objectivity in the evaluation process, the MIM process before and after the treatment of children was videotaped. Baseline scores were measured using an independent evaluator. The evaluator, who measured the baseline score, remeasured the score based on the MIM video conducted af- ter Theraplay. It was rated as 0.5 , median score with or without symptoms, for items that were not revealed during the MIM process. The evaluators consisted of two psychiatrists. The final score was based on the scores agreed upon by the two.

\section{Statistics}

Statistical analysis was conducted using SPSS version 24 (IBM Corp., Armonk, NY, USA). To check the effectiveness of the Theraplay, the total score and the sub-category score of the K-SCQ were compared before and after Theraplay. The Kolmogorov-Smirnov test was used because of the small sample size, and it was confirmed that they did not follow a normal distribution. As a result, before and after treatment, comparisons were made using the Wilcoxon signed-rank test. The critical value was set at 0.05 .

\section{RESULTS}

\section{Participants' demographic characteristics}

There were no significant differences in the demographic characteristics between boys and girls (Table 2).

\section{Post-treatment changes}

The total and subcategory scores in children before and after treatment are shown in Table 3. A total of 16 showed a

Table 1. Marschak interaction method

\begin{tabular}{|c|c|}
\hline $\begin{array}{l}\text { Activity } \\
\text { sequence }\end{array}$ & Interaction task \\
\hline 1 & $\begin{array}{l}\text { Parents have one animal doll that sounds, and give the other to the child. Parents and children play with two dolls. } \\
\text { (structure, engagement) }\end{array}$ \\
\hline 2 & $\begin{array}{l}\text { Parents make shapes out of blocks. Then the parents say to the child, 'Make yourself equal to this in four blocks.', } \\
\text { and suggest five or eight pieces. (structure, challenge) }\end{array}$ \\
\hline 3 & Parents and children apply lotion to each other (or parents apply lotion to the child). (nurture) \\
\hline 4 & Parents tell their children about when they were just born. (nurture) \\
\hline 5 & Parents teach their children what they don't know. (structure, challenge) \\
\hline 6 & Parents leave the room for a minute, leaving the child behind. (nurture) \\
\hline 7 & Parents and children play familiar games together. (engagement) \\
\hline 8 & Parents and children feed each other (or parents feed their children). (nurture) \\
\hline
\end{tabular}

Table 2. Demographic data

\begin{tabular}{|c|c|c|c|}
\hline & Boys & Girls & Total \\
\hline Sex, n (\%) & $17(85)$ & $3(15)$ & $20(100)$ \\
\hline Age of children (month) & $59(28)$ & 53 & $56(26)$ \\
\hline Age of father (year) & $42(8)$ & 41 & $41.5(7)$ \\
\hline Education period of father (year) & $16(2)$ & 16 & $16(2)$ \\
\hline Age of mother (year) & $37(6)$ & 39 & $37(6)$ \\
\hline Education period of mother (year) & $16(0)$ & 18 & $16(2)$ \\
\hline Children of taking other treatment, $\mathrm{n}$ & 9 & 3 & 12 \\
\hline
\end{tabular}

Values are presented as median (inter quartile range) unless otherwise indicated. 
Table 3. The K-SCQ total and sub-items score by patient

\begin{tabular}{|c|c|c|c|c|c|c|c|c|}
\hline \multirow{2}{*}{ Participant } & \multicolumn{4}{|c|}{ Baseline } & \multicolumn{4}{|c|}{ Post treatment } \\
\hline & Total & A & B & $C$ & Total & A & B & $\mathrm{C}$ \\
\hline 1 & 16.0 & 9.0 & 5.0 & 1.0 & 11.0 & 4.0 & 7.0 & 0.0 \\
\hline 2 & 8.5 & 5.5 & 3.0 & 0.0 & 6.0 & 4.0 & 2.0 & 0.0 \\
\hline 3 & 4.5 & 2.5 & 2.0 & 0.0 & 4.5 & 2.5 & 2.0 & 0.0 \\
\hline 4 & 7.0 & 4.0 & 3.0 & 0.0 & 6.0 & 4.0 & 2.0 & 0.0 \\
\hline 5 & 10.0 & 7.0 & 3.0 & 0.0 & 6.0 & 4.0 & 2.0 & 0.0 \\
\hline 6 & 13.5 & 6.5 & 6.0 & 0.0 & 10.0 & 4.0 & 6.0 & 0.0 \\
\hline 7 & 11.0 & 5.0 & 5.0 & 0.0 & 6.0 & 4.0 & 2.0 & 0.0 \\
\hline 8 & 6.0 & 4.0 & 2.0 & 0.0 & 6.0 & 4.0 & 2.0 & 0.0 \\
\hline 9 & 9.0 & 5.0 & 4.0 & 0.0 & 6.0 & 4.0 & 2.0 & 0.0 \\
\hline 10 & 18.0 & 6.0 & 7.0 & 4.0 & 11.0 & 6.0 & 4.0 & 1.0 \\
\hline 11 & 7.0 & 4.0 & 3.0 & 0.0 & 6.0 & 4.0 & 2.0 & 0.0 \\
\hline 12 & 14.0 & 5.0 & 6.0 & 2.0 & 9.0 & 5.0 & 4.0 & 0.0 \\
\hline 13 & 7.0 & 4.0 & 3.0 & 0.0 & 8.0 & 4.0 & 4.0 & 0.0 \\
\hline 14 & 20.0 & 10.0 & 8.0 & 1.0 & 11.0 & 5.0 & 6.0 & 0.0 \\
\hline 15 & 6.0 & 4.0 & 2.0 & 0.0 & 7.0 & 4.0 & 3.0 & 0.0 \\
\hline 16 & 14.0 & 5.0 & 7.0 & 1.0 & 14.0 & 6.0 & 6.0 & 1.0 \\
\hline 17 & 15.0 & 6.0 & 7.0 & 1.0 & 13.0 & 5.0 & 7.0 & 1.0 \\
\hline 18 & 11.0 & 5.0 & 5.0 & 0.0 & 6.0 & 4.0 & 2.0 & 0.0 \\
\hline 19 & 6.0 & 4.0 & 2.0 & 0.0 & 6.0 & 4.0 & 2.0 & 0.0 \\
\hline 20 & 8.0 & 4.0 & 2.0 & 1.0 & 6.0 & 4.0 & 2.0 & 0.0 \\
\hline Average & 10.6 & 5.3 & 4.3 & 0.6 & 7.9 & 4.3 & 3.5 & 0.2 \\
\hline Median & 9.5 & 5.0 & 3.5 & 0.0 & 6.0 & 4.0 & 2.0 & 0.0 \\
\hline
\end{tabular}

Total: entire item (SCQ total score). A: social interaction domain, B: communication domain, C: restricted, repetitive, and homogeneous behavioral pattern area, K-SCQ: The Korean version of the Social Communication Questionnaire

decrease in total score, while one had an increase in total score, and three had no change in total score. The change in the total score for 16 out of 20 children was the result of improved symptoms. These score changes were statistically significant $(\mathrm{p}=0.001)$ when analyzed using the Wilcoxon signedrank test (Table 4). When analyzed by subcategory, the changes were statistically significant in both the social interaction areas $(\mathrm{p}=0.011)$, the communication areas $(\mathrm{p}=0.025)$, and the limited and repetitive behavioral pattern areas $(\mathrm{p}=0.039)$. When boys and girls were analyzed separately, boys showed statistically significant changes in total scores $(\mathrm{p}=0.002)$, social interaction areas $(\mathrm{p}=0.028)$, communication areas $(\mathrm{p}=$ $0.017)$, and limited and repetitive behavioral patterns ( $\mathrm{p}=0.039$ ). In the case of girls, the total score and changes in all subcategories were not statistically significant, which was thought to be due to the small number of samples $(n=3)$.

\section{DISCUSSION}

In this study, an average of 20 Theraplay programs were conducted for children with ASD. Comparing before and af-
Table 4. Change of K-SCQ total and sub-items score through the Theraplay (Wilcoxon signed rank test)

\begin{tabular}{lcl}
\hline & $z$ (change) & $p$ \\
\hline Total $(n=20)$ & & \\
Total* & -3.269 & 0.001 \\
A & -2.532 & 0.011 \\
B & -2.236 & 0.025 \\
C & -2.060 & 0.039 \\
Boys $(n=17)$ & & \\
Total* & -3.053 & 0.002 \\
A & -2.200 & 0.028 \\
B & -2.377 & 0.017 \\
C & -2.060 & 0.039 \\
Girls $(n=3)$ & & \\
Total* & -1.069 & 0.285 \\
A & -1.342 & 0.180 \\
B & -1.000 & 0.317 \\
C & 0.000 & 1.000 \\
\hline
\end{tabular}

*Total: entire item (SCQ total score). A: social interaction domain, B: communication domain, C: restricted, repetitive, and homogeneous behavioral pattern area, K-SCQ: The Korean version of the Social Communication Questionnaire

ter Theraplay, the total score of the SCQ decreased. The pattern of change could be assessed as having reduced symptoms of ASD.

Previous studies on early childhood and development of infants claimed that the mother's upbringing was an important indicator for infant development in 'interrelational care' coordinated with the body and emotions of infants [22-24]. Such interrelational care is promoted and developed reciprocally because it is an interactive process between mother and child and is not unidirectional [23]. Thus, qualitative flaws in social interactions among children with autism do not respond appropriately to parental behavior, which can lead to deterioration of the quality and quantity of relationships.

In this study, we identified changes in children with autism through the Theraplay that elicit active participation by parents of autistic children by viewing 'relationship' rather than individuals as a treatment target. Therefore, there are reports that strengthening the positive effects of parents, such as appropriate parental counseling and parent education programs, can help promote and develop appropriate behavior for children with autism [25]. We also tried to contribute to the presentation of treatments that could be helpful for children with autism by reviewing the need for Theraplay in actual clinical trials based on previous research results [26,27].

In this study, the total SCQ scores for children with ASD decreased overall through Theraplay. Even when examined by subcategories, symptoms after treatment in all areas of social interaction, communication, and limited and repetitive 
behavioral patterns were significantly improved. Given that the subcategory is a key symptom of ASDs, Theraplay can be considered helpful throughout the symptoms of ASD in children.

The strength of this study is that the psychiatrists who were not involved in the Theraplay evaluated the K-SCQ based on MIM progress. The changes before and after treatment could be analyzed specifically to match the characteristics of ASDs. In addition, subjective bias was reduced by separating therapists and evaluators. So far, there have been few papers on the effects of the therapy. In this work, it is meaningful that it may have created a foundation to prove the validity of the theraplay intervention effects that have not yet been proven to be effective.

This study had some limitations. First, the number of samples was low, which may have prevented the validity of the results. In the case of girls, there were only three subjects. Next, as there was no control group, the evaluator's influence was not completely controlled. Therefore, it is difficult to generalize the results to conclude that Theraplay has a clinical effect. Third, the baseline score was 4.5-20 points, so the difference in the underlying condition of each child may be insufficient to explain the overall result. The overall score may have been underestimated because of the behavioral aspects not revealed during the MIM process. Fourth, a parent evaluation scale (K-SCQ) was used to view the overall status for a short-term evaluation in the MIM process. As the psychiatrist used the parent evaluation scale, it was difficult to accurately measure all items. Finally, the long-term effects of Theraplay could not be explained by checking only the changes in children immediately after the completion of the Theraplay.

It is common to think that ASDs affect various areas in terms of function and that integrated treatment must be performed for many years to confirm their effectiveness in terms of treatment. Unlike previous studies, it is meaningful that a relatively short-term six-month intervention in this study could confirm changes in the SCQ scale scores. However, it is believed that a follow-up study of longer-term follow-up and a study with a control group will be needed.

\section{CONCLUSION}

In this study, we confirmed that SCQ scores improved overall through Theraplay. These results might serve as a basis for strengthening the idea that Theraplay can be helpful for children with autism. The results of this study are also expected to help develop and supplement Theraplay programs for children with autism in the future.

\section{Acknowledgments}

None

\section{Conflicts of Interest}

The authors have no potential conflicts of interest to disclose.

\section{Author Contributions}

Conceptualization: Bongseog Kim. Data curation: Bongseog Kim. Formal analysis: Yoonyoung Chang. Funding acquisition: Bongseog Kim. Investigation: Yoonyoung Chang. Methodology: Bongseog Kim, Miwon Youn. Project administration: Bongseog Kim. Resources: Miwon Youn. Software: Yoonyoung Chang. Supervision: Bongseog Kim. Validation: Bongseog Kim. Visualization: Yoonyoung Chang. Writingoriginal draft: Yoonyoung Chang. Writing_review \& editing: Bongseog Kim.

\section{ORCID iDs}

$\begin{array}{ll}\text { Yoonyoung Chang } & \text { https://orcid.org/0000-0002-3699-6431 } \\ \text { Bongseog Kim } & \text { https://orcid.org/0000-0002-2534-6986 }\end{array}$

\section{REFERENCES}

1) American Psychiatric Association. Diagnostic and statistical manual of mental disorders: DSM-5(R). 5th ed. Washington, DC: American Psychiatric Association;2013. p.50-59.

2) Kim JS, Yoo HJ, Cho IH, Park TW, Son JW, Chung US, et al. Clinical characteristics of developmental regression in autism spectrum disorders. J Korean Acad Child Adolesc Psychiatry 2011;22:141-148.

3) Hong KE. Korean textbook of child psychiatry. 2nd ed. Seoul: Hakjisa;2014. p.145-166.

4) Vriend JL, Corkum PV, Moon EC, Smith IM. Behavioral interventions for sleep problems in children with autism spectrum disorders: current findings and future directions. J Pediatr Psychol 2011; 36:1017-1029.

5) World Health Organization (WHO). Autism spectrum disorders Fact Sheet. Updated 2021. [cited 2021 Jan 1]. Available from URL: https://www.who.int/news-room/fact-sheets/detail/autism-spectrum-disorders.

6) Roane HS, Fisher WW, Carr JE. Applied behavior analysis as treatment for autism spectrum disorder. J Pediatr 2016;175:27-32.

7) Virues-Ortega J, Julio FM, Pastor-Barriuso R. The TEACCH program for children and adults with autism: a meta-analysis of intervention studies. Clin Psychol Rev 2013;33:940-953.

8) Flippin M, Reszka S, Watson LR. Effectiveness of the Picture Exchange Communication System (PECS) on communication and speech for children with autism spectrum disorders: a meta analysis. Am J Speech Lang Pathol 2010;19:178-195.

9) Dawson G, Rogers S, Munson J, Smith M, Winter J, Greenson J, et al. Randomized, controlled trial of an intervention for toddlers with autism: the Early Start Denver Model. Pediatrics 2010;125:e17-e23.

10) Park HA, Kim JI, Kim YN, Park SB, Yang YH, Lee YS, et al. Autism spectrum disorder and behavioral intervention: an updated review. J Korean Acad Child Adolesc Psychiatry 2015;26:86-93.

11) Yoon MW, Kim YK, Shin HJ, Jeon EH, Kim YJ, Trans. Theraplay. Seoul: Hakjisa;2011. p.31-118. (Original work: Booth PB, Jernberg AM. Theraplay: helping parents and children build better relationships through attachment-based play. 3rd ed. San Francisco: John Wiley \& Sons, Inc.;2009.)

12) Robison M, Lindaman SL, Clemmons MP, Doyle-Buckwalter K, Ryan M. "I Deserve a Family": the evolution of an adolescent's behavior and beliefs about himself and others when treated with theraplay in residential care. Child and Adolescent Social Work Journal 2009;26:291-306.

13) Sung YH. Theraplay I. 1st ed. Seoul: Hyung-sul;2000. p.27-92. 
14) Yang YH. Review of early intervention for children with autism spectrum disorder: focused on randomized controlled trials. J Korean Acad Child Adolesc Psychiatry 2019;30:136-144.

15) Hiles Howard AR, Lindaman S, Copeland R, Cross DR. Theraplay impact on parents and children with autism spectrum disorder: improvements in affect, joint attention, and social cooperation. International Journal of Play Therapy 2018;27:56-68.

16) Lindaman SL, Booth PB, Chambers CL. Assessing parent-child interactions with the Marschack Interaction Method (MIM). In: Gitlin-Weiner K, Sandgrund A, Schaefer C, editors. Play diagnosis and assessment. 2nd ed. New York: John Wiley \& Sons, Inc.;2000. p. 371-400.

17) Yoo HJ, Trans. Korean version of Social Communication Questionnaire (SCQ). Seoul: Hakjisa;2008. p.5-40. (Original work: Rutter M, Bailey A, Lord C. The Social Communication Questionnaire. Los Angeles: Western Psychological Services. 2003.)

18) Lord C, Risi S, Lambrecht L, Cook EH Jr, Leventhal BL, DiLavore PC, et al. The autism diagnostic observation schedule-generic: a standard measure of social and communication deficits associated with the spectrum of autism. J Autism Dev Disord 2000;30:205-223.

19) Lord C, Rutter M, Le Couter A. Autism diagnostic interview-revised: a revised version of a diagnostic interview for caregivers of individuals with possible pervasive developmental disorders. J Autism Dev Disord 1994;24:659-685.
20) Witwer AN, Lecavalier L. Autism screening tools: an evaluation of the social communication questionnaire and the developmental behaviour checklist-autism screening algorithm. J Intellect Dev Disabil 2007;32:179-187.

21) Kim JH, Sunwoo HJ, Park SB, Noh DH, Jung YK, Cho IH, et al. A validation study of the Korean version of social communication questionnaire. J Korean Acad Child Adolesc Psychiatry 2015;26: 197-208.

22) Bowlby J. Attachment and loss: attachment. Vol. 1. 2nd ed. New York: Basic;1969. p.177-264.

23) Winnicott DW. The theory of the parent-infant relationship. Int J Psychoanal 1960;41:585-595.

24) Jacobson E. The self and the object world: vicissitudes of their infantile cathexes and their influence on ideational and affective development. Psychoanal Study Child 1954;9:75-127.

25) Im SB, Hong KE. Changes of psychopathology and development in autistic children through parent education program. J Korean Acad Child Adolesc Psychiatry 1990;1:161-171.

26) Yun MW. A study on theraplay for attachment development enhancement of infancy. Korean Journal of Child Welfare 2004;2: $55-74$.

27) Lee SH. An ethnographic study about the effects of the motherchild therapy program in enhancing mother-child interaction. Korean Journal of Child Welfare 2005;3:1-24. 